\title{
ESTUDO DA GESTÃO E DISPOSIÇÃO FINAL DOS RESÍDUOS SÓLIDOS URBANOS (RSU) NO MUNICÍPIO DE CAMPO GRANDE (MS)
}

Dayane Freitas de Medeiros José Carlos De Jesus Lopes**

RESUMO: No Brasil, em agosto de 2010, foi instituída a Política Nacional de Resíduos Sólidos (PNRS) tentando-se nortear estratégias que agreguem valor aos resíduos e propiciem inclusão e controle social, instruindo o Estado para o adequado manejo, seguindo padrões internacionais. Com o intuito de constatar o grau de envolvimento e percepção da economia de Campo Grande em um novo prisma de desenvolvimento, o presente trabalho teve como objetivo analisar as operacionalidades do tratamento e disposição final dos RSU em Campo Grande, pós-promulgação da Política Nacional dos Resíduos Sólidos, Lei n ${ }^{\circ} 12.305$, através de visita ao aterro controlado do município, qual a gestão e destinação dos Resíduos Sólidos Urbanos (RSU) na capital de Mato Grosso do Sul, utilizando-se de técnicas de pesquisa qualitativa, sendo elas a descritiva e a exploratória. Foi constatado que o município ainda se encontra distante dos padróes acordados e dos modelos internacionais de sustentabilidade.

PALAVRAS-CHAVE: Desenvolvimento Sustentável; Meio Ambiente; Política Nacional dos Resíduos Sólidos.

\section{MANAGEMENT AND FINAL DISPOSAL OF URBAN SOLID WASTES IN CAMPO GRANDE, BRAZIL}

ABSTRACT: The National Policy for Solid Wastes was established in Brazil in August 2010 to monitor strategies that aggregate rate to wastes and provide inclusion and social control so that the State would acquire adequate management according to international standards. Current assay analyzed the operationality of the treatment and final disposal of solid wastes in Campo Grande MS Brazil so that the degree of involvement and perception of the economy of Campo Grande could be assessed

\footnotetext{
"Graduada no Curso de Ciências Econômicas na Universidade Federal de Mato Grosso do Sul (UFMS), Brasil; E-mail: daaymedeiros@gmail.com

${ }^{* *}$ Doutor em Meio Ambiente e Desenvolvimento, pela Universidade Federal do Paraná (UFPR); Docente Adjunto da Universidade Federal de Mato Grosso do Sul (UFMS), Brasil.
} 
within a new development phase. The above occurred after the publication of Law 12305 on the National Policy for Solid Wastes when a visit was planned to the sewage treatment landfill of the municipality to evaluate the management and disposal of Solid Wastes in the capital city of Mato Grosso do Sul by quality, descriptive and exploratory research techniques. Results show that the municipality is a long way off from standards and international models of sustainability.

KEY WORDS: Sustainable Development; Environment; National Policy for Solid Wastes.

\section{INTRODUÇÃO}

O desenvolvimento sustentável significa compatibilidade do crescimento econômico com desenvolvimento humano e qualidade ambiental. Neste sentido, preconiza o atendimento das necessidades humanas em dois aspectos: aumentando o potencial de produção e assegurando às gerações presentes e futuras as mesmas oportunidades. Isso exige uma transição dos padrões insustentáveis de produção, troca e consumo, hoje dominantes, para padrões sustentáveis de desenvolvimento que privilegiem a satisfação de necessidades básicas da população com eficiência econômica, mas também com prudência ecológica.

A problemática dos resíduos sólidos urbanos se agrava no espaço urbano devido ao processo de expansão das cidades. As localidades urbanas vêm sofrendo transformações ambientais danosas decorrentes dos crescimentos populacionais, industriais e da oferta de bens de consumo descartáveis, gerando diversos tipos de resíduos como orgânicos, secos, tóxicos, tecnológicos, que necessitam cada vez mais de aterros sanitários para sua disposição (MENDES, 2011).

Sem a infraestrutura necessária para oferecer a destinação adequada a esses resíduos, muitas áreas urbanas criam soluções improvisadas ou emergenciais, dando origem a uma série de transtornos que se reflete em graves problemas de saúde pública e ameaças ao meio ambiente (CUNHA, 2011).

O gerenciamento inapropriado dos resíduos gera riscos de contaminação do solo, de rios e de águas subterrâneas decorrentes do chorume e dos gases, especialmente dióxido de carbono $\left(\mathrm{CO}_{2}\right)$ e metano $\left(\mathrm{CH}_{4}\right)$, provenientes da digestão dos 
dejetos. Além disso, contribui para a proliferação de parasitas e doenças. Percebe-se, portanto, que o tratamento e disposição final inadequada dos resíduos ocasionam um custo social alto.

O panorama nacional da destinação final de resíduos é alarmante, principalmente nas pequenas e médias cidades. No Brasil, cerca de 59\% dos resíduos produzidos, de um total de 150 mil toneladas por dia, são destinados a lixões, sem qualquer tratamento ou seleção prévia (IBGE, 2010). Em 2008, apenas 405 dos 5.564 municípios brasileiros realizavam coleta seletiva.

Em agosto de 2010, foi sancionada a Lei 12.305 que institui a Política Nacional dos Resíduos Sólidos (PNRS). O documento é constituído de instrumentos e diretrizes para traçar ações estratégicas que viabilizem processos capazes de agregar valor aos resíduos de forma a aumentar a capacidade competitiva do setor produtivo, propiciar a inclusão e o controle social e nortear Estados e municípios para o adequado manejo de resíduos sólidos. Atribui ainda ao poder público e à coletividade a responsabilidade pela efetividade das ações que envolvam os resíduos sólidos gerados, isto é, estabelece uma gestão integrada de resíduos (PNRS, 2011).

$\mathrm{O}$ Artigo $2^{\mathrm{O}}$ do referido documento discorre sobre as principais diretrizes do programa, dentre elas a não geração, redução, reutilização e tratamento de resíduos sólidos, bem como destinação final ambientalmente adequada dos rejeitos; em busca do desenvolvimento de processos que modifiquem os padrões de produção e consumo tornando-os sustentáveis; incentivo ao uso de matérias-primas e insumos derivados de materiais recicláveis e reciclados; articulação entre as diferentes esferas do Poder Público, visando à cooperação técnica e financeira para a gestão integrada de resíduos sólidos; integração dos catadores de materiais recicláveis nas ações que envolvam o fluxo de resíduos sólidos (PNRS, 2011).

A implantação da lei aprovada trará reflexos positivos no âmbito social, ambiental e econômico, pois não só tende a diminuir o consumo dos recursos naturais, como proporcionar a abertura de novos mercados, a exemplo das usinas específicas em reciclagem, gerando emprego e renda, o que conduz à inclusão social e diminui os impactos ambientais provocados pela disposição inadequada dos resíduos. Sendo assim, a lei insere o desenvolvimento sustentável no manejo de resíduos sólidos do país (PNRS, 2011). 
Com uma população superior a 786.797 habitantes (IBGE, 2010), e uma expansão alarmante da geração de resíduos, Campo Grande necessita despertar para a problemática do lixo. Nas últimas duas décadas, a produção de resíduos no município aumentou em torno de quatro vezes, superando 172 mil toneladas em 2005 (MINISTÉRIO DE MINAS E ENERGIA, 2008). Portanto, é indispensável à adequação do Plano Diretor municipal às exigências da PNRS, o que passa pela implementação de políticas públicas que atenuem os impactos da produção de RSU. Além disso, esse direcionamento prioriza o desenvolvimento sustentável da cidade.

Sendo assim, identificar o modelo de gestão e disposição final dos RSU produzidos em Campo Grande constitui o primeiro passo para verificar o grau de inserção e a postura do poder público municipal frente ao novo prisma do desenvolvimento. Partindo das premissas legais, como a própria PNRS, é possível estabelecer uma comparação entre as políticas públicas vigentes e as políticas que seriam adequadas ao tratamento dos resíduos sólidos urbanos gerados na localidade, indicando qual seria o direcionamento do município para ir ao encontro dos novos rumos do desenvolvimento.

O objetivo do presente estudo foi analisar as operacionalidades do tratamento e disposição final dos RSU em Campo Grande, pós-promulgação da Política Nacional dos Resíduos Sólidos, Lei n 12.305.

\section{MATERIAL E MÉTODOS}

Localizado em $-20.44^{\circ} \mathrm{W}$ e $-50.64^{\circ} \mathrm{N}$, o município de Campo Grande, capital do Estado de Mato Grosso do Sul, ocupa um território de $8.096 \mathrm{~km}^{2}$, onde se encontra distribuída uma população de aproximadamente 786.797 habitantes (IBGE, 2010). Com um PIB de 8.944.688 reais e um PIB per capita de 12.346 reais (IBGE, 2010), a quantidade de resíduos sólidos urbanos (RSU) coletados em Campo Grande vem crescendo nos últimos 20 anos.

A proporção total coletada em 2005, superior a 172 mil toneladas, é em torno de quatro vezes maior que a coletada em 1985, que não chegavam a 44 mil toneladas, como divulgado pelo Aproveitamento Energético dos Resíduos Sólidos Urbanos de Campo Grande (MS) (MINISTÉRIO DE MINAS E ENERGIA, 2008). 
Os resíduos sólidos urbanos em Campo Grande são coletados e dispostos no aterro sanitário denominado de Dom Antônio Barbosa II desde 21 de novembro de 2012, sob responsabilidade da CG Solurb Soluções e da Prefeitura Municipal. O local está situado na região sul da cidade, Anhanduizinho, no anel viário BR-060 (saída para São Paulo), no bairro Dom Antônio Barbosa, conforme a Figura 1.

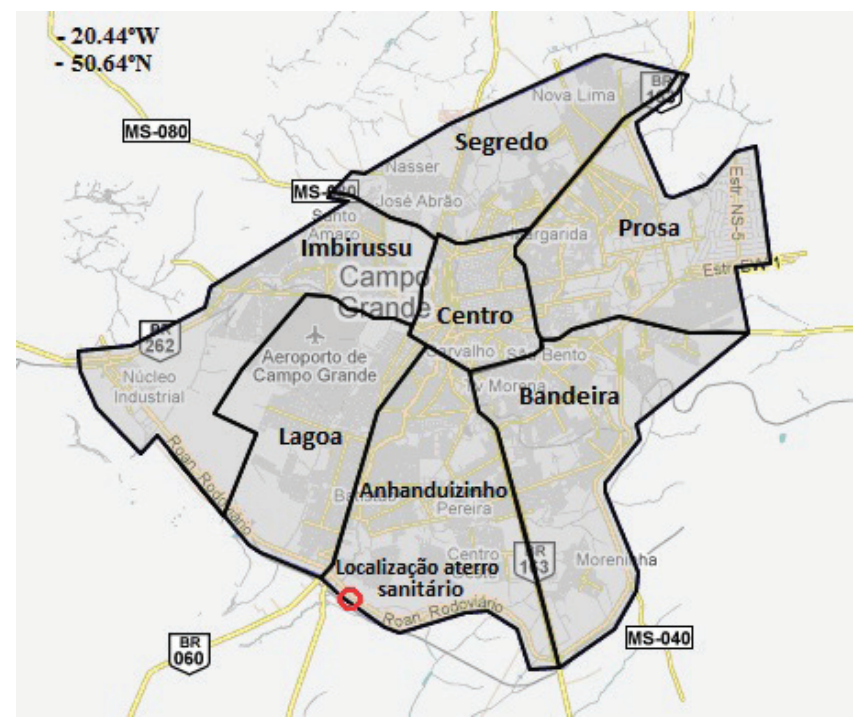

Figura 1. Localização do aterro sanitário de Campo Grande (MS) Fonte: SEINTRHA (2008)

Para os fins deste estudo, foram adotadas técnicas de pesquisa qualitativa, sendo elas a descritiva e a exploratória. A pesquisa qualitativa pressupõe que há uma relação dinâmica entre a realidade e o sujeito que não pode ser transformada em números e é descritiva, dado que a interpretação dos fenômenos e a atribuição de significados são fundamentais no processo de investigação, sendo o pesquisador seu instrumento chave.

No que se refere aos meios de investigação qualitativa, tratou-se de uma pesquisa de caráter documental e bibliográfico. Assim sendo, houve uma observância em textos produzidos por estudiosos da área de Desenvolvimento Sustentável, Resíduos Sólidos Urbanos, além da própria PNRS, objetivando verificar a operacionalidade do município de Campo Grande no que tange essas premissas. 
A investigação documental, por sua vez, deu-se por meio da análise de relatórios específicos - Abrelpe, CEMPRE, publicações das atas do Fórum do lixo do município - além da participação da pesquisadora em palestras, workshops, audiências públicas, semana do meio ambiente, voluntária/ouvinte no projeto CATAFORTE, visitas técnicas ao aterro controlado e à Usina de Triagem de Recicláveis, levantamento de dados secundários em órgãos públicos como PLANURB e da atual concessionária responsável por esse processo no município, SOLURB CG Soluções Ambientais.

Além do levantamento de informações na Secretaria Municipal de Meio Ambiente e Desenvolvimento Urbano (SEMADUR), com base no Plano de Saneamento Básico-Gestão Integrada de Resíduos Sólidos, com as promulgações de leis e decretos que instituem as diretrizes da Política Nacional dos Resíduos Sólidos, dados que permitiram a contextualização do problema. Por conseguinte, a metodologia versou com o acúmulo de dados empíricos para dar maior embasamento às considerações desenvolvidas no trabalho.

Em 08 de setembro de 2011, foi realizada uma visita ao aterro controlado do município de Campo Grande (MS), de caráter técnico com vistas a identificar o gerenciamento e disposição final dos RSU. Sob supervisão dos responsáveis técnicos, realizou-se uma conversa sem um roteiro pré-definido com os mesmos, os quais apresentaram o local de disposição dos respectivos tipos de resíduos dentro do espaço do aterro controlado.

\section{RESULTADOS E DISCUSSÃO}

A quantidade de resíduos sólidos urbanos (RSU) produzidos em Campo Grande (MS) vem crescendo a taxas elevadas nos últimos 20 anos. A média mensal de Resíduo Sólido Domiciliar coletado, em 2011, até o mês de agosto, é de 19.390 toneladas. Observa-se um aumento de mais de 200\% do que era coletado em 1990, quando a média mensal era de 6.401 toneladas. O Gráfico 1 demonstra a série da média mensal da massa de Resíduo Domiciliar coletado em Campo Grande entre 1990 e 2011. 


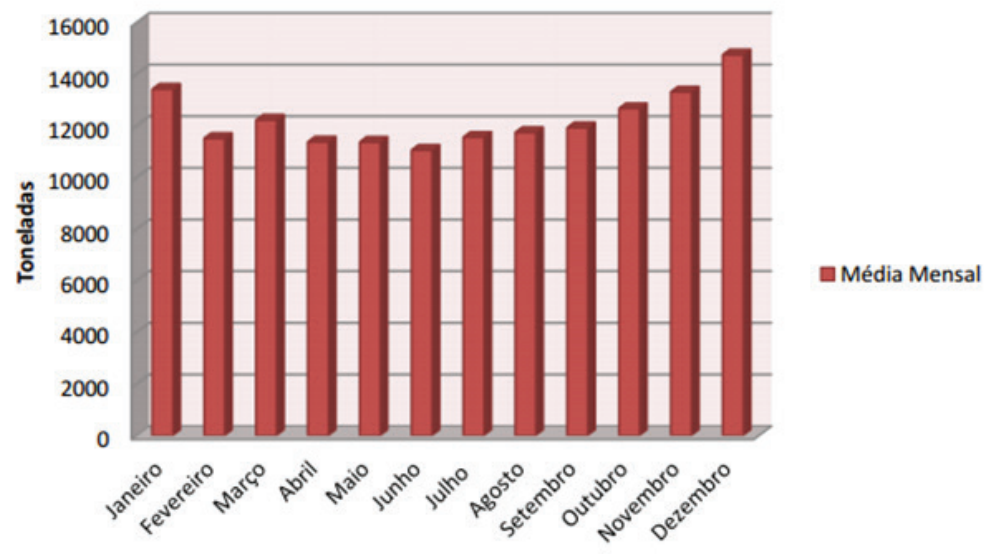

Gráfico 1. Média Mensal de Resíduo Domiciliar de 1990-2011.

Fonte: Seinthra (2011), citado por Lima (2011)

De acordo com o gráfico, em específico ao resíduo sólido domiciliar urbano (domicílios, residenciais e comerciais), é possível perceber um comportamento sazonal no decorrer nos anos; no entanto, nos meses de março e julho, constata-se que são os de menor produção. A população campo-grandense, segundo a SEINTHRA (2010), consome um volume médio que varia de 0,8 a 1,0 $\mathrm{kg}$ por dia.

O RSU de Campo Grande é composto, segundo o Ministério de Minas e Energia (2008), por 60\% de materiais não recicláveis, sendo essa massa composta principalmente por matéria orgânica putrescível, madeira, panos e trapos. Os 40\% restantes são compostos por materiais recicláveis, coletados no município, sendo o papel e papelão (embalagens, jornais, livros, cadernos, caixas, etc.) e o plástico (embalagens, garrafas PET, copos descartáveis, etc.) responsáveis por $81 \%$ de toda sua massa reciclável.

Quando se trata de coleta seletiva, percebe-se mesmo que de forma não generalizada a tentativa de adequação do município neste processo. De acordo com a SEINTHRA, a coleta seletiva é o primeiro passo para a reciclagem, que permitirá disseminar a diretriz da responsabilidade compartilhada.

A coleta seletiva atende 120 bairros de Campo Grande; cada bairro recebe um caminhão coletor uma vez por semana, além de existir locais de entrega voluntária - LEV'S e os chamados Ecopontos em supermercados, farmácias, para facilitar a participação da população. A Usina de Tratamento de Recicláveis - UTR 
- do município ainda está em construção; quando finalizada será responsável pela separação dos recicláveis em parceira com as cooperativas.

Através da promulgação da Lei 12.305 sancionada em 2010, o município de Campo Grande, na forma institucional da gestão dos resíduos sólidos, acompanhou este avanço, prova disso são as leis e decretos promulgados no Diário Oficial do município - DIOGRANDE.

Com a Política Nacional de Resíduos Sólidos em vigor, os municípios deveriam apresentar um Plano Municipal de Gestão Integrada de Resíduos Sólidos e, neste aspecto de sustentabilidade, ampliar seus objetivos e metas, pois o acesso aos recursos da União direcionados à gestão dos resíduos sólidos dependerá da apresentação dos planos. Desta forma, em abril de 2012, foi apresentado o PMGIRS do município de Campo Grande.

O Plano Municipal de Gestão Integrada de Resíduos Sólidos de Campo Grande apresenta as seguintes metas: regular as práticas, direitos e obrigações públicas e provadas dos geradores de resíduos sólidos; coletar separadamente dos demais resíduos os resíduos recicláveis e/ou reaproveitáveis, de forma a atender todos os bairros e/ou regiões; segregar $100 \%$ dos resíduos recicláveis e/ou reaproveitáveis dispostos incorretamente e coletados através de coleta convencional; implantar equipamentos para acondicionamento adequado de grandes volumes de resíduos, gerados em locais com grande concentração de pessoas; ampliar para 100\% o atendimento com a coleta de resíduos sólidos em todo o perímetro urbano e distritos; desativar a atual área (aterro controlado) utilizada como disposição dos resíduos municipais além de promover a inclusão social dos catadores que atuam no aterro controlado.

Em um primeiro momento foi possível perceber o imenso volume de resíduos dispostos de maneira inadequada, sem qualquer seleção prévia ou tratamento diferenciado conforme as especificidades de cada resíduo. Devido a essa disposição incorreta observou-se a exposição a céu aberto de valas/canaletas de chorume, percorrendo toda a extensão do aterro e as proximidades do córrego Formiguinha (chorume a $1 \mathrm{~km}$ do córrego), ocasionando a contaminação do solo e dos catadores. No período da visita, constatou-se a possibilidade de livre entrada de indivíduos para despejo de seus próprios resíduos.

Também chamou a atenção a presença dos catadores coletando resíduos sem a mínima proteção necessária, não há um controle de acesso aos catadores, 
existindo aproximadamente 200 deles no aterro controlado. Os catadores fazem em média sete bags por dia, cada bag pesa $60 \mathrm{~kg}$, como mostrado na Figura 2.

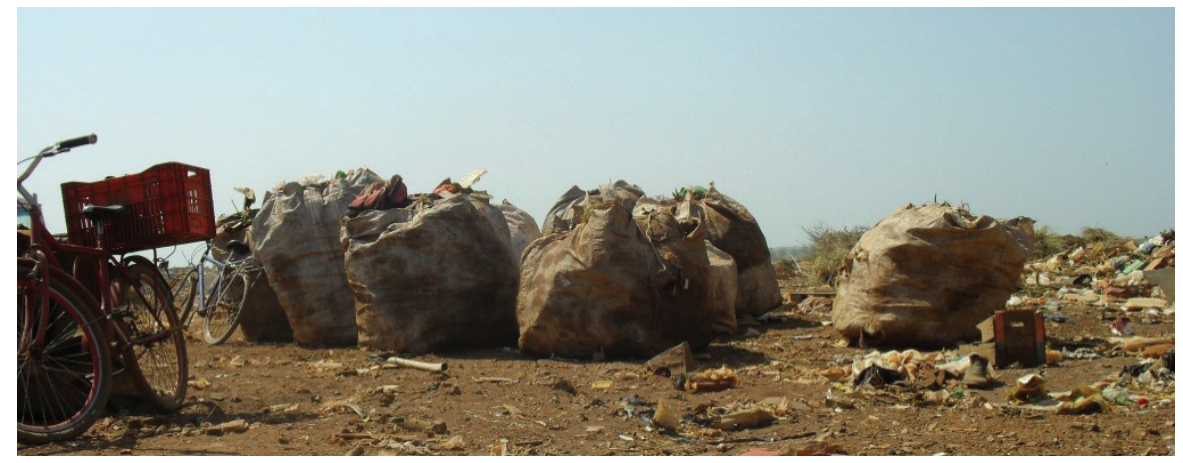

Figura 2. Bags coletadas pelos catadores dentro do aterro controlado em Campo Grande (MS) Fonte: Acervo da pesquisadora (setembro de 2011)

Antes da promulgação da Lei 12.305/2010, não havia qualquer espaço destinando à vigilância e segurança (guaritas). Até os próprios responsáveis indicaram a necessidade de pelo menos doze pessoas para realizar esta atividade. No entanto, apenas em 2012, nota-se a presença de um aviso, proibindo a entrada de pessoas não autorizadas, intervenção esta feita tardiamente, pois não evitou uma tragédia, no fim de 2011, onde um menino de apenas nove anos foi soterrado em meio aos resíduos e chorume.

O atual aterro controlado, no bairro Dom Antônio Barbosa, originou-se em 1984. Em 2010, a produção anual de resíduos chegou a 252 mil toneladas; neste mesmo período, através do Termo de Ajustamento de Conduta (TAC), que foi firmado entre a prefeitura e o Ministério Público Estadual (MPE), e a promulgação da Política Nacional de Resíduos Sólidos (PNRS), estipulou-se que em 2012 o aterro controlado seria desativado, e iniciar-se-iam as operações do aterro sanitário Dom Antônio Barbosa II, juntamente com a ativação da Usina de Triagem (UTR).

No dia 28 de novembro de 2013 foi inaugurado o Aterro Sanitário Dom Antônio Barbosa II, a concessionária CG Solurb Soluções assume a responsabilidade sobre a coleta e disposição final dos resíduos sólidos urbanos e demais obrigações pelos próximos 25 anos. $\mathrm{O}$ aterro controlado foi desativado e passará por um processo de recuperação no período de um ano e meio, pois, devido ao que foi propos- 
to pelo PNRS, o aterro controlado está inserido no Plano de Recuperação de Área Degradada (PRAD).

Foi feito um investimento no valor de $\mathrm{R} \$ 2.259 .882,54$, para implantação de Usina de Triagem no Aterro Sanitário de Campo Grande (MS), através do Governo Federal e Prefeitura Municipal de Campo Grande. No entanto, a UTR ainda não se encontra em plena capacidade de funcionamento, conforme Figuras 3 e 4.

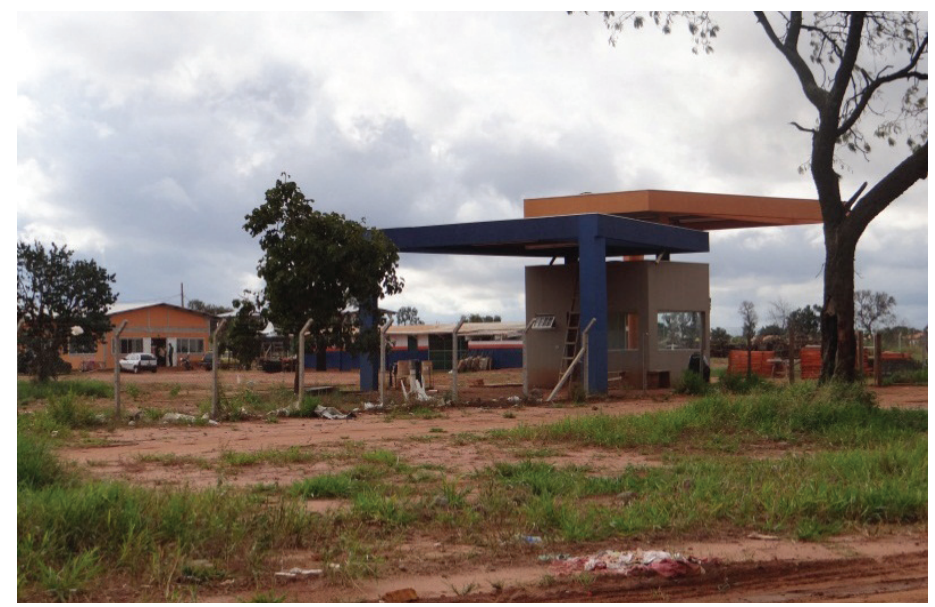

Figura 3. Instalações Inacabadas da UTR

Fonte: Acervo da pesquisadora (junho de 2013)

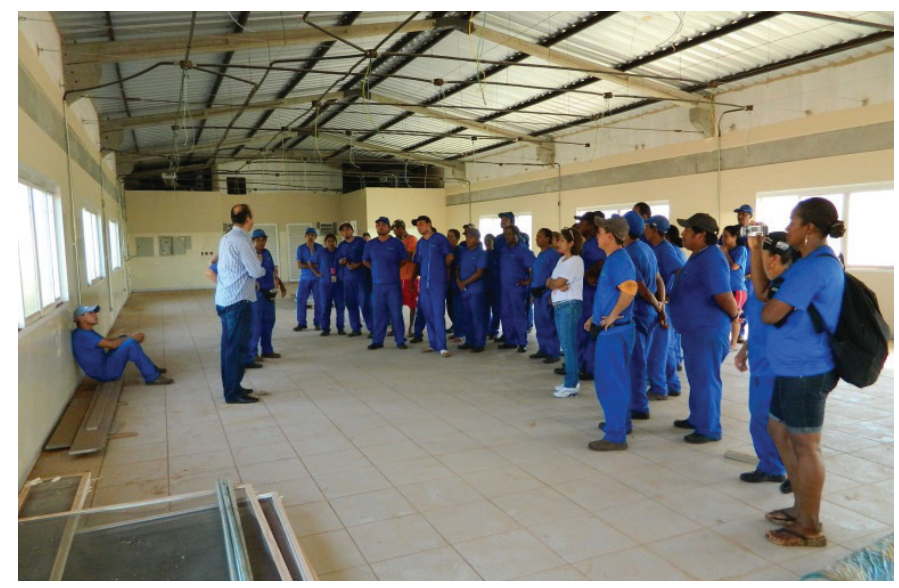

Figura 4. Galpão de triagem dentro da UTR Fonte: Fórum do Lixo 
De acordo com o Plano Municipal de Gestão Integrada de Resíduos Sólidos de Campo Grande, as metas e ações estabelecidas que envolvam os catadores consistem em coletar de forma separada os resíduos recicláveis e reaproveitáveis, além de promover a inclusão social dos catadores que atuam no aterro controlado.

O Programa de Coleta Seletiva adotado pela Prefeitura Municipal de Campo Grande, desde julho de 2011 evidenciou o início de um avanço no processo de gerenciamento dos resíduos sólidos no município. Adotar tal medida traz alguns benefícios como a redução em $4 \%$ do volume de lixo urbano destinado ao aterro controlado, o que permite, a longo prazo, aumento da vida útil do local de destinação final dos resíduos, além de estimular cada vez mais o processo de reciclagem, permitindo a geração de emprego e renda.

Dentro do âmbito da inclusão do catador de materiais recicláveis/reutilizáveis, surge o Cataforte, um programa desenvolvido pela Secretaria Nacional de Economia Solidária (Senaes) e a Fundação Banco do Brasil, que promove ação de formação e assessoria técnica para o setor de reciclagem dos resíduos sólidos. $\mathrm{O}$ Projeto Cataforte em Mato Grosso do Sul é executado pela Organização Não-Governamental Economia Solidária, Preservação Ambiental e Desenvolvimento Social - ONG ESPADS, com apoio da Fundação Banco do Brasil, Petrobras, Ministério do Trabalho, Governo Federal e orienta os polos de cooperativismo de reciclagem nos bairros Nova Lima, Nova Campo Grande, Coophavila II, Rita Viera, Noroeste, Nova lima e Dom Antônio Barbosa.

\section{CONSIDERAÇÕES FINAIS}

O conceito de Desenvolvimento Sustentável, na questão dos resíduos sólidos, é pertinente, pois possibilita diminuir a quantidade de insumos utilizados em uma mesma produção. E torna possível através de implementação de novas tecnologias, no processo de reutilização e reciclagem de materiais, cumprir e fortalecer com uma das diretrizes da Política Nacional dos Resíduos Sólidos (PNRS), sancionada pela Lei 12.305, ações como a logística reversa, gestão integrada e sustentável dos resíduos e a responsabilidade compartilhada. 
O estudo da gestão dos resíduos sólidos foi pertinente para a pesquisa, pois exemplifica que as diretrizes da PNRS, trabalhando o conceito de logística direta e reversa, e da responsabilidade compartilhada, demonstra que apesar de todo o aspecto legal, e da promulgação do mais inovador marco regulatório no país, dentro do município de Campo Grande as mudanças operacionais, quando se trata da coleta, tratamento e disposição final, não correspondem de forma abrangente às premissas do Desenvolvimento Sustentável e da PNRS, rejeitando a hipótese estudada.

Em visita ao local de destinação de resíduos sólidos urbanos do município de Campo Grande, e com a pesquisa realizada, constatou-se que a realidade está muito distante do que se apregoa a legislação. Pode-se perceber um verdadeiro descaso com a gestão dos resíduos sólidos urbanos das naturezas estudadas. Entende-se que não apenas o poder público deve ser responsabilizado pela gestão dos resíduos, mas consumidores e fabricantes também possuem parcela de comprometimento.

É preciso, portanto, que se organize essa política junto com a sociedade civil organizada, conscientes de seu papel, convergindo para uma racionalização da cadeia produtiva do lixo, com uma ação sinérgica, de forma que se consiga transformar os resíduos em potenciais ambientais, sociais, políticos e econômicos, não mais sendo visto como problema.

\section{REFERÊNCIAS}

ACURIO, G.; ROSSIN, A.; TEIXEIRA, P. F.; ZEPETA, F. Diagnóstico de la situación del manejo de resíduos sólidos municipales en América Latina y el Caribe. Washington/DC: BID/OPAS, 1997.

ANDRADE, M. M. Como preparar trabalhos para cursos de pós-graduação: noções práticas. 5. ed. São Paulo: Altas, 2002.

BARONE, V. Prefeitura assina hoje TAC que solucionará a questão do lixo na Capital. 2009. CGNotícias, Disponível em: < http://www.capital.ms.gov.br/cgnoticias/noticiaCompleta?id_not=6109>. Acesso em: 24 maio 2011.

BIDONE, R. A.; POVINELLI, J. Conceitos básicos de resíduos sólidos. São Carlos: EESC/USP, 1999. 
CALDERONI, S. Os bilhões perdidos no lixo. 3. ed. São Paulo: Humanistas, 1998. $346 \mathrm{p}$.

CUNHA, V.; CAIXETA FILHO, J. V. Gerenciamento da Coleta de Resíduos Sólidos Urbanos: estruturação e aplicação de modelo não-linear de programação por metas. Gestão \& Produção, v.9, n.2, p.143-161, ago. 2002. Disponível em: < http://www. scielo.br/pdf/gp/v9n2/a04v09n2.pdf>. Acesso em: $01 \mathrm{dez} .2011$.

CRESWELL, J. W. Projeto de pesquisa: métodos qualitativo, quantitativo e misto. Porto Alegre: Artmed, 2007.

DEMAJOROVIC, J. Da política tradicional de tratamento de lixo à política de gestão de resíduos sólidos: as novas prioridades. RAE Ambiental, v. 35, n. 3, p. 89-93, 1995. Disponível em: < http://www.scielo.br/pdf/rae/v35n3/a10v35n3.pdf > . Acesso em: 10 nov. 2012.

GIL, A. C. Como elaborar projetos de pesquisa. São Paulo: Atlas, 1991.

GOVERNO FEDERAL. Política Nacional de Resíduos Sólidos. 2010. Disponível em: < http://www.camara.gov.br/sileg/integras/501911.pdf>. Acesso em: 20 nov. 2012.

LIMA, N. C. Economia solidária: um estudo de caso sobre o processo de coleta e reciclagem de resíduos sólidos urbanos na cidade de Campo Grande-MS. 2011. Monografia (Curso de Ciências Econômicas) - Universidade Federal do Mato Grosso do Sul, 2011.

LOPES, J. C. J. Resíduos Sólidos Urbanos: consensos, conflitos e desafios na gestão institucional na Região Metropolitana de Curitiba/PR. 2007. 250f. Tese (Curso de Doutorado em Meio Ambiente e Desenvolvimento) - Universidade Federal do Paraná, Curitiba, 2007.

MENDES, A. M. T. Valor Econômico: análise setorial. [s.l.; s.n.], agosto de 2011.

MINISTÉRIO DE MINAS E NERGIA - MME. Aproveitamento energético dos Resíduos Sólidos Urbanos de Campo Grande, MS. Rio de Janeiro: EPE, 2008. Disponível 
em: $\quad$ <http://www.epe.gov.br/mercado/Documents/S\%C3\%A9rie\%20Estudos\%20 de\%20Energia/20081208_1.pdf >. Acesso em: abr. 2013.

NEVES, J. L. Pesquisa qualitativa: características, usos e possibilidades. Caderno de Pesquisas em Administração, São Paulo, v. 1, n. 3, 1996.

ORGANIZAÇÃO DAS NAÇÕES UNIDAS. Relatório Brundtland (1987). Disponível em: <http://www.onu.org.br/a-onu-em-acao/a-onu-e-o-meio-ambiente/>. Acesso em: 30 jan. 2013.

PLANO NACIONAL DE RESÍDUOS SÓLIDOS. 2011. Disponível em: < http://www. mma.gov.br/estruturas/253/_publicacao/253_publicacao02022012041757.pdf $>$. Acesso em: jan. 2013.

SANTOS, J. Os caminhos do lixo em Campo Grande: disposição dos resíduos sólidos na organização do espaço urbano. Campo Grande: UCDB, 2000.

SEMADUR. Prefeitura Municipal de Campo Grande (MS). Relatório Coleta Seletiva Julho, 2011. Campo Grande: SEMADUR, 2011.

SEMADUR. Prefeitura Municipal de Campo Grande (MS). Relatório Coleta Seletiva Agosto, 2011. Campo Grande: SEMADUR, 2011.

SISTEMA NACIONAL DE INFORMAÇÕES SOBRE SANEAMENTO. SNIS. Sistema Nacional de Informações sobre Saneamento: diagnóstico do manejo de resíduos sólidos urbanos. 2009. Brasília, DF: MCIDADES. SNSA, 2009. Disponível em: < http:// www.coletasolidaria.gov.br/menu/noticias/http-www-pmss-gov-br-snis-paginacarrega-php-ewrerterterterter-16> . Acesso em: 30 jun. 2011.

SECRETARIA MUNICIPAL DE INFRAESTRUTURA, TRANSPORTE E HABITAÇÃO. SEINTRHA. Resíduos Sólidos. Disponível em: <http://www.prefeituradecampogrande.com.br/seintrha/canaisTexto?id_can=993 > . Acesso em: mar. 2013.

VÁZQUEZ, E. Introdução. In: PROJETO Entulho bom: reciclagem de entulho para a produção demateriais de construção. Salvador: UFBA, 2001. p. 22-25. WCED. 
OUR COMMON FUTURE. Report of the World Commission on Environment and Development. Disponível em: < http://www.un-documents.net/ocf-02.htm\#I>. Acesso em: abr. 2013.

Recebido em: 18 de julbo de 2013 Aceito em: 11 de fevereiro de 2014 